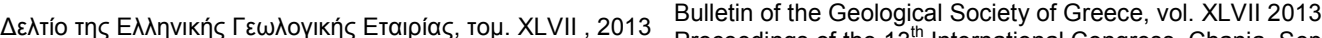

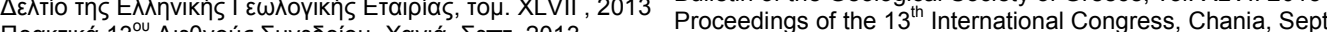

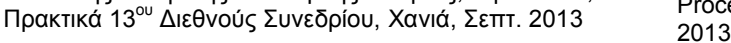

\title{
THE CLEARWATER PROJECT: PRELIMINARY RESULTS FROM THE GEOPHYSICAL SURVEY IN TYMPAKI, CRETE, GREECE
}

\author{
Vafidis A. ${ }^{1}$, Andronikidis N. ${ }^{1}$, Hamdan H. ${ }^{2}$, Kritikakis G. ${ }^{1}$, Economou N. ${ }^{1}$, \\ Panagopoulos G. ${ }^{1}$, Soupios P. ${ }^{3}$, Steiakakis E. ${ }^{1}$ and Manoutsoglou E. \\ ${ }^{1}$ Technical University of Crete, Department of Mineral Resources Engineering, \\ vafidis@mred.tuc.gr \\ ${ }^{2}$ A.C.E.S. Riyadh, Abn Rashiq Street, Building No. 6, Riyadh, Saudi Arabia, \\ ${ }^{3}$ Technological Educational Institute of Crete - Branch of Chania, Department of Natural \\ Resources \& Environment
}

\begin{abstract}
One of the most important environmental problems in coastal areas is the salinization of ground water. The groundwater contamination due to seawater intrusion is usually caused by a violation of a delicate hydrogeological balance that exists between freshwater and seawater in coastal aquifers. The development of a methodology for the prediction of the systematic sea water intrusion can contribute to the planning of effective prevention measures in the coastal areas. The geophysical techniques offer a suitable non-invasive method for determining the geometric characteristics of an aquifer and monitoring the saline water intrusion. Among all geophysical techniques, the most successful methods, concerning the detection of salinization in the coastal areas, are the electric resistivity and electromagnetic methods. Seismic methods can also help in providing further geological information for the stratigraphy. In this work, we present the preliminary results from the geoelectrical survey conducted in Tympaki basin (Herakleio, Greece) within the framework of the project "geophysiCaL basEd hydrogeologicAl modeling to pRevent pollution from sea WATER intrusion at coastal areas".

Key words: Seawater intrusion, electrical tomography, Tympaki, CLEARWATER.
\end{abstract}

\section{Пєрí}

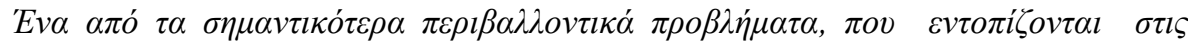

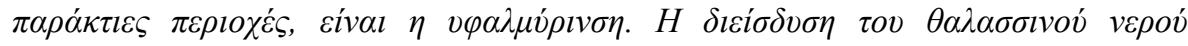

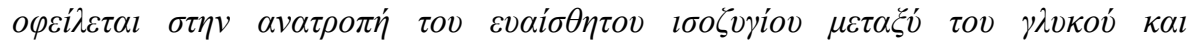

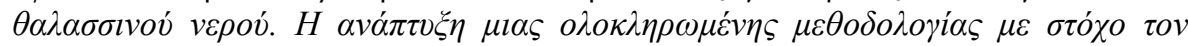

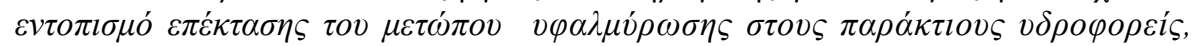

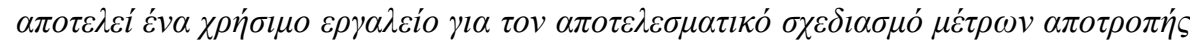

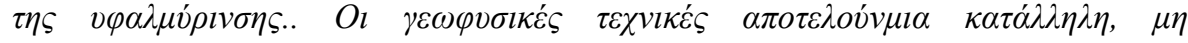

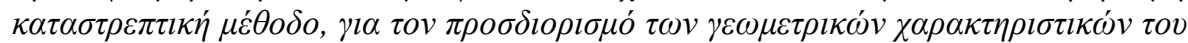

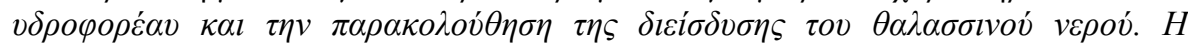

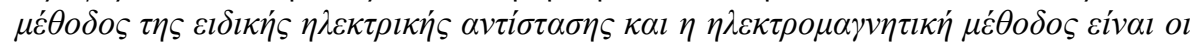

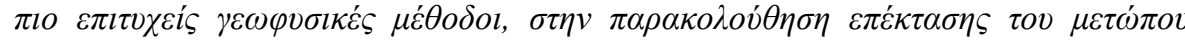

$\underline{\text { XLVII, No } 3-1338}$ 


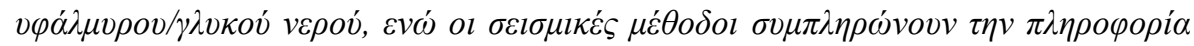

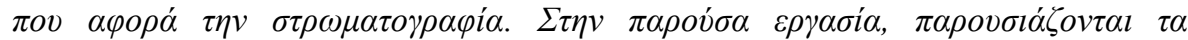

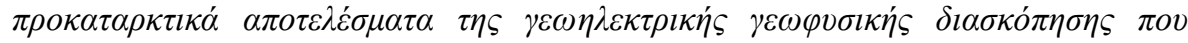

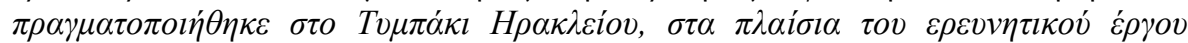
"geophysiCaL basEd hydrogeologicAl modeling to pRevent pollution from sea WATER intrusion at coastal areas».

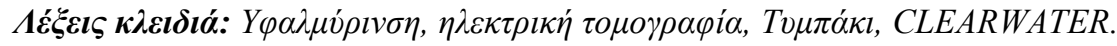

\section{The CLEARWATER Project}

Coastal areas are densely populated, since they provide the best conditions for both economical development and quality of life. On the other hand, these regions suffer more than other areas from scarcity of fresh groundwater due to seawater intrusion into coastal aquifers. In most cases, the balance between freshwater/seawater is disturbed by groundwater over pumping and other human activities that lower groundwater level and ultimately cause seawater intrusion into the coastal area.

The consequences of this phenomenon can be catastrophic for the coastal aquifers, especially in the areas where the climate is arid or semi-arid, the groundwater is inadequate and the rainfall is the main source of freshwater. In such cases, the problem of sea water intrusion is irreversible and the effective prediction tools are of vital importance for preventing salinization.

The project "CLEARWATER" (geophysiCaL basEd hydrogeologicAl modeling to pRevent pollution from sea WATER intrusion at coastal areas) aims to develop an integrated approach for prediction the saltwater intrusion in coastal area that enhances the planning effective prevention measures in coastal areas. This methodology is based on modelling, monitoring and management of the groundwater. The key idea is the use of combinedgeophysical methods in order to monitor the evolution of the salinity boundaries, while the innovation of this project is the development of a comprehensive geophysical data processing tool which will guide the modelling and management process providing additional hydrogeological parameters.

The geophysical methods provide continuous subsurface structural information with low costs. Among all geophysical techniques, the most successful methods, concerning the detection of seawater intrusion, are the electrical and electromagnetic methods due to their sensitivity to the presence of the chlorine ion. Seismic methods can also help in providing information to locate fracture zones.

The geophysical methods have been widely used for assessing intrusion of seawater into coastal aquifers. Specifically, the electrical resistivity (Imhof et al., 2001; Kuras et al., 2005; Nguyen et al., 2009; Hamdan and Vafidis, 2009) and electromagnetic methods (Danielsen et al., 2003; Kafri and Goldman, 2005; Nielsen et al., 2007) have been proven to be powerful tools for the detection of the salt water presence in the aquifer. On the other hand, seismic methods are also widely used for depth imaging of complex structures (Haeni, 1986; Jarvis and Knight, 2002; Balia et al., 2003). The conventional way of combining the information provided by these methods is by means of joint interpretation of their processed data. This requires an experienced interpreter and often it's difficult to find a geological model which satisfies all available geophysical data.

Recently, different techniques have been developed to accommodate the interpretation process. Most of these techniques are based on the joint inversion of the different data sets, in order to achieve a unified geological model which will satisfy all the available geophysical data. The joint inversion techniques reduce the uncertainty arising from the non-uniqueness of the individual inversion (Zhang and Morgan, 1997; Gallardo and Meju, 2003; Candansayar and Tezkan, 2008). However, the efficiency of these techniques is still examined, especially in regions of complex geology. The CLEARWATER project focuses on the development of electric, electromagnetic and seismic joint inversion schemes, targeting to be applied at selected coastal areas for the detection of sea water intrusion.

$\underline{\text { XLVII, No } 3-1339}$ 
More specifically, in the project CLEARWATER, two study areas were selected, namely Tympaki, Crete, Greece and Bafra Plain, Samsun, Turkey, using the following criteria: (a) The site must face sea water intrusion problems at early stages. (b) It must have agricultural, tourist or any other economical and social activity. (c) It must be located in the Black Sea region or in other region facing similar sea water intrusion problems. (d) It is necessary to have access to geological hydrogeological data and boreholes.

A total of 8 sites were proposed from the partners. The evaluation system developed for the needs of the site selection is based on 15 factors extracted from the above criteria. Each factor is given a grade on a scale to 5 , where the highest grade (5) denotes the most propitious condition for the application of the developed methodology, while zero value denotes that the site is inappropriate. In this work, we present the preliminary results from the geoelectrical survey conducted in Tympaki area in Crete.

\section{Geological and Hydrogeological Setting of Tympaki Area, Crete, Greece}

Tympaki area is located in the south central part of of Crete (Fig. 1). Tympaki is part of the Messara geological basin and was selected as test site for the application of the methodologies which will be developed by the project CLEARWATER. Farming, mainly greenhouses, citrus and olive groves comprise the main human activities in Tympaki resulting to widely developed irrigation systems. More than 7,800 hectares are cultivated, 4,000 of which are irrigated. Irrigation is performed exclusively by groundwater extraction, amounting to $7,000,000 \mathrm{~m}^{3}$ per year.

In Crete, a large number of faults indicate an intense tectonic activity in the region. The tectonic setting affected the integrity and continuity of the lithostratigraphic units and the faults bring in contact different lithostatigraphic units with different hydrogeological characteristics.

Neogene deposits in Messara basin have undergone multidirectional extensional tectonic events with intervals of small, in duration and intensity degree of compression. Tympaki sub-basin is separated from the rest Messara basin by Festos horst. It is filled with Neogene deposits, which are regarded as aquitard and it separates hydrogeologically the Tybaki basin from the eastern part of Messara basin. There is only an approximately $2 \mathrm{~km}$ - wide passage through the horst, on which Geropotamos river flows towards the west.

Tympaki sedimentary basin was formed and evolved during Miocene. Pleistocene and Holocene deposits dominate in the study area. The Neogene formation crops out mainly to the north of the study area and underlies the Pleistocene deposits.

The Pre-Neogene formation crops out mainly to the north of the study area. The geological contact of the Neogene with the Pre-Neogene formations (mainly represented by limestones) is tectonic in the form of a fault with major direction W-SW to E-NE.

All deposits show heterogeneous sequences of conglomerates, cobbles, sands, marls and clays with rapid lateral and vertical lithological changes, making the correlation of layers a difficult task.

Generally, the marly Neogene deposits act practically as impermeable layers, while the coarser and uncemented quaternary deposits are the permeable units. The upper Pleistocene and recent deposits have an average thickness of $120 \mathrm{~m}$ in the south part of the basin and $90 \mathrm{~m}$ in the north while the thickness of Pleistocene deposits is more than $200 \mathrm{~m}$.

The availiable geological and hydrogeological studies (show that three hydrogeological units exist in the area: a) the Upper Pliocene to Quaternary formation aquifer, b) the Middle Miocene to Upper Pliocene formation aquitard and c) the Mesozoic aquifuge formations. The continuity of those formations is interrupted by several faults resulting in a block-faulting structure. 


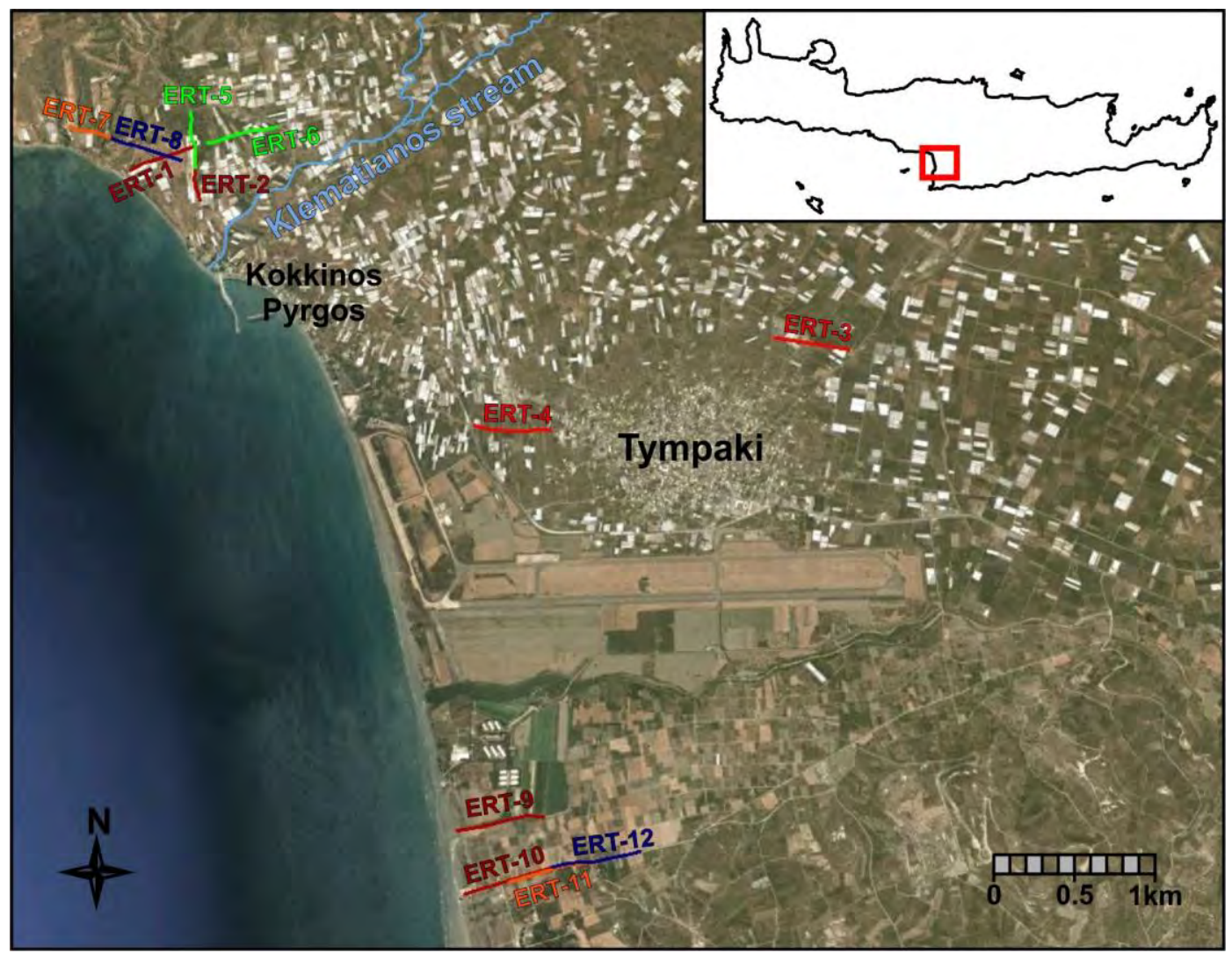

Figure 1 - The area under investigation and the surveyed lines $\left(\right.$ Google earth $\left.^{\mathrm{TM}}\right)$.

The analysis and evaluation of the pumping test data (FAO, 1972), indicate that the average transmissivity $(\mathrm{T})$ of the Neogene and Quaternary deposits reaches $1.7 \times 10^{-1} \mathrm{~m}^{2} / \mathrm{sec}$ corresponding to permeability (k) $1.8 \times 10^{-3} \mathrm{~m} / \mathrm{sec}$ (based on the apparent thickness of the formations/ drilling depth). Moreover, the storage coefficient (S) was estimated at $7.5 \times 10^{-4}$, while the specific yield (Sy) was calculated equal to 0.145 . However, the above mentioned values are not considered representative for the geological formations of the aquifer. Specifically, the values of $\mathrm{T}$ and $\mathrm{k}$ are very high compared to values referred in literature ( $\mathrm{k}$ should vary from $10^{-4}$ to $10^{-6} \mathrm{~m} / \mathrm{sec}$ ), while the large difference between $\mathrm{S}$ and Sy suggests confined aquifer, that is not the case.

These discrepancies in the results of the pumping tests with the expected values from the hydrogeological parameters, are mainly due to the following reasons:

- The wells are not perforated over the full thickness of the aquifer; therefore significant errors arise from the usage of the conventional methods (Dupuit, Jacob, Recovery method).

- The aquifer (Neogene and Quaternary deposits) is heterogeneous (with alternating coarse and fine materials); therefore the permeability varies with depth.

- The well screens extend for all the thickness of each permeable formation (aquifer).

- Aquifuge layers (clay, marl) which overlay water bearing formations (where the screens are extended), create local pressure conditions.

According to a review of the pumping test programme (Paritsis, 2005), transmissivity values in the alluvium exceed $1 \times 10^{-1} \mathrm{~m}^{2} / \mathrm{sec}$. Storage coefficient values are on average around $10 \%$ and in coarser grained layers probably reach $15 \%$ or more. Transmissivities for the Lower Pleistocene range from $5 \times 10^{-3}$ to $4 \times 10^{-2} \mathrm{~m}^{2} / \mathrm{sec}$, and the average value being around $1 \times 10^{-2} \mathrm{~m}^{2} / \mathrm{sec}$. Storage 
coefficients are estimated to be around $6 \%$. Well yields in the alluvium can exceed $300 \mathrm{~m}^{3} / \mathrm{h}$ with a drawdown of a few meters and specific capacities of $100 \mathrm{~m}^{3} / \mathrm{h} / \mathrm{m}$ drawdown. The pumping levels range between 3 and $7 \mathrm{~m}$ above the sea level.

Well yields, ca $200 \mathrm{~m}^{3} / \mathrm{h}$, have been attained also in the Pleistocene, although the specific capacities are remarkably lower (about 15 to $40 \mathrm{~m}^{3} / \mathrm{h} / \mathrm{m}$ drawdown). Pumping levels range between 20 and $40 \mathrm{~m}$ below the sea level.

At the central part of the plain, between Tymbaki and the Klematianos stream (Fig. 1), well yields $100 \mathrm{~m}^{3} / \mathrm{h}$ with specific capacities of 20 to $40 \mathrm{~m}^{3} / \mathrm{h} / \mathrm{m}$ drawdown are observed.

\section{Preliminary Results of the Geophysical Survey}

Geophysical data have been collected using electrical/electromagnetic geophysical methods in order to map the saline water intrusion. Twelve (12) electrical tomography lines of total $5913 \mathrm{~m}$ length were surveyed, using the Wenner-Schlumberger array. 55 electrodes were used in spacings $8.5,9$ and $10 \mathrm{~m}$, resulting to line length ranged from $459 \mathrm{~m}$ to $540 \mathrm{~m}$. Sting R1/Swift AGI system collected apparent resistivity data at 21 depth levels per line. The apparent resistivities were subsequently inverted using RES2DINV ${ }^{\mathrm{TM}}$ software. The maximum depth of investigation was $100 \mathrm{~m}$. Figure 1 shows the surveyed lines. Based on the preliminary evaluation of the geophysical data and the existing geological and borehole data, we observe that the electrical resistivity ranges from $5 \mathrm{Ohm} . \mathrm{m}$ (fine materials of the Pleistocene to recent deposits) to more than $120 \mathrm{Ohm} . \mathrm{m}$ (coarse materials). Saline water saturated zones of the Pleistocene and alluvium aquifers exhibit very low electrical resistivity values. Typical geophysical sections show that the Pleistocene deposits at the central part of the plain between Tympaki and Klematianos stream and at depths less than $100 \mathrm{~m}$ don't encounter saline intrusion. In particular, the geoelectrical section of ERT-12 (Fig. 2) indicates a low resistivity clay layer whose thickness is around $30 \mathrm{~m}$ on top of a higher resistivity zone, attributed to coarser material. According to the geoelectrical section ERT-4 (Fig. 3 ), the Pleistocene formations are highly heterogeneous. The lower resistivity zone at depths greater than $80 \mathrm{~m}$ in ERT-3 (Fig. 4) is attributed to Neogene formations according to a nearby borehole. Figures 5 and 6 present geoelectrical sections from the NE part of Tympaki sub-basin, where groundwater contamination due to sea water intrusion has been observed. More specifically, geoelectrical section ERT-2 indicates that seawater intrusion (very low resistivity) zone is present at depth greater than $30 \mathrm{~m}$. Similar images are given by the electromagnetic method TEM which scanned the Tympaki sub-basin.

\section{Conclusions}

The preliminary investigation at Tympaki sub-basin, where Neogene deposits unconformably lie over the pre-Neogene basement and Pleistocene to recent deposits lie over the Neogene formation, indicate that the aquifers in these formations are heterogeneous with alternations of coarse and fine materials and exhibit seawater intrusion at depths less than $100 \mathrm{~m}$ at NW Tympaki.

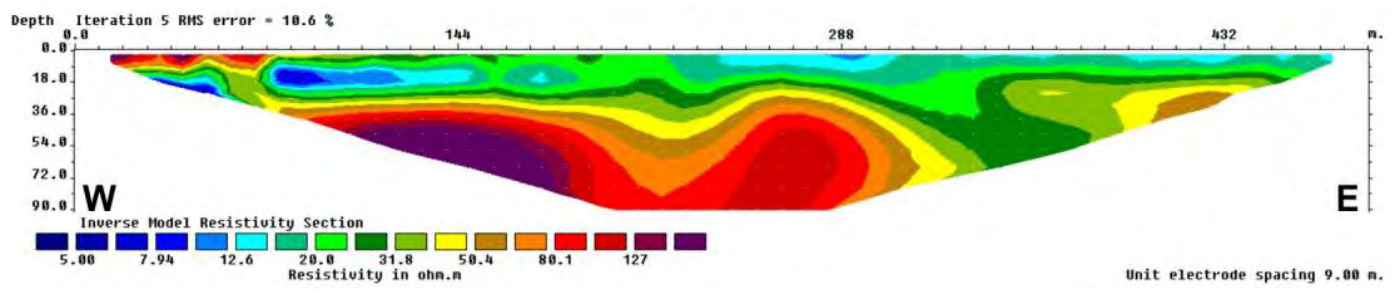

Figure 2 - Geoelectrical section of ERT-12. 


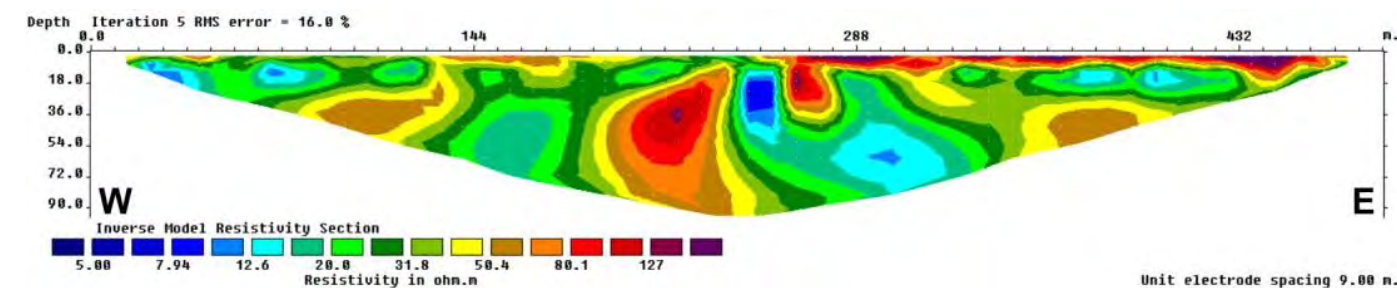

Figure 3 - Geoelectrical section of ERT-4.

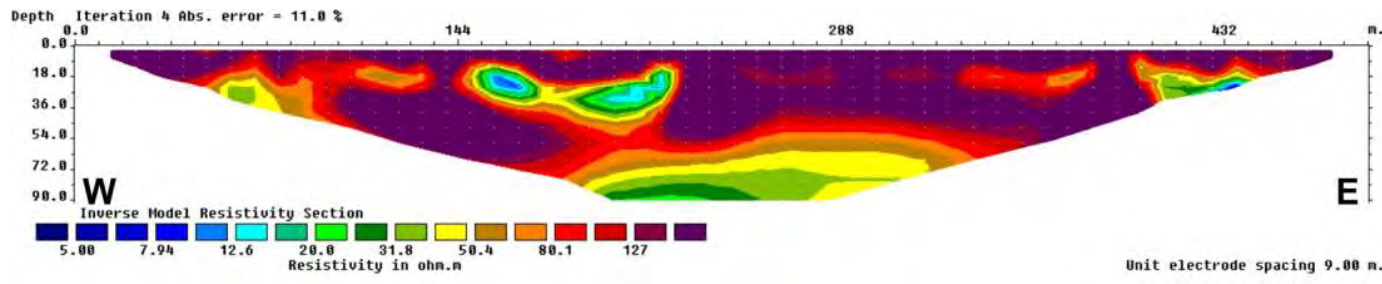

Figure 4 - Geoelectrical section of ERT-3.

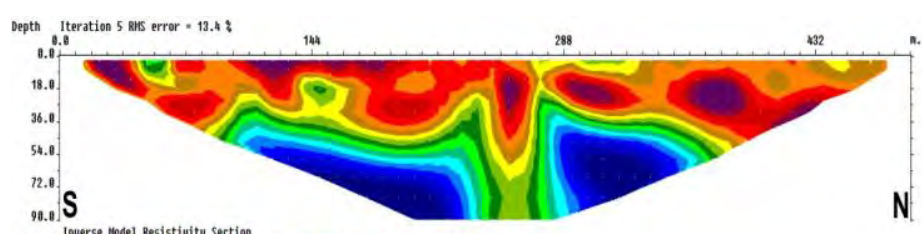

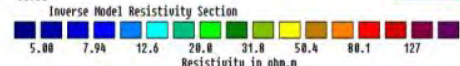

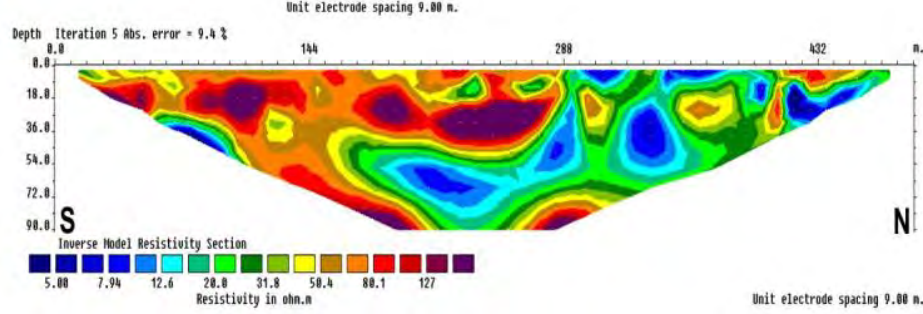

Figure 5 - Geoelectrical sections of ERT-2 (up) and ERT-5 (down). They are 46\% overlapped.
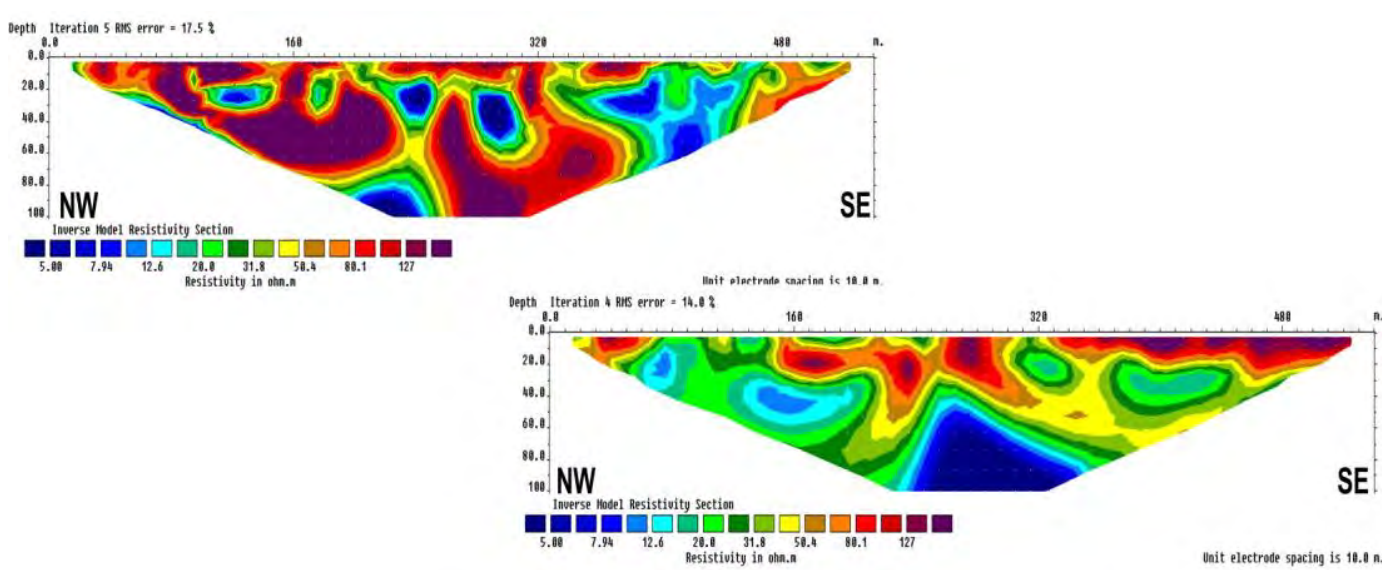

Figure 6 - Geoelectrical sections of ERT-7 (up) and ERT-8 (down). They are 40\% overlapped.

XLVII, No 3 - 1343 


\section{Acknowledgments}

This research has been financed by Greek national funds through the Operational Program "Education and Lifelong Learning" of the National Strategic Reference Framework (NSRF) Research Funding Program: BS-ERA.NET. Networking on Science and Technology in the Black Sea Region.

\section{References}

Balia R., Gavaudo E., Ardau F. and Ghiglieri G. 2003. Geophysical approach to the environmental study of a coastal plain, Geophysics, Vol. 68, No. 5, 1446-1459.

Candansayar M.E. and Tezkan B. (2008). Two-dimensional joint inversion of radiomagnetotelluric and direct current resistivity data, Geophysical Prospecting, 56, 737-749.

Danielsen J.E., Auken E., Jorgensen F., Sondergaard V.H., Sorensen K. L. 2003. The application of the transient electromagnetic method in hydrogeophysical surveys, Journal of Applied Geophysics, 53, 181-198.

FAO, 1972. Study of the water resources and their exploitation for irrigation in eastern Crete Greece. Drillings and pumping tests in Messara AGL:SF/GRE 17/31 tech rep.26, UNDP, Iraklio.

Gallardo L.A. and Meju M.A. 2003. Characterization of heterogeneous near-surface materials by joint 2D inversion of DC resistivity and seismic data, Geophys. Res. Lett., 30(13), 1658.

Haeni F.P. 1986. Application of seismic refraction methods in groundwater modeling studies in New England, Geophysics, Volume 51, No. 2, 236-249.

Hamdan H., Vafidis A. 2009. Inversion techniques to improve the resistivity images over karstic structures, Proceedings of the 15th European Meeting of Environmental and Engineering Geophysics, 3-5 September 2009 Dublin, Ireland.

Imhof A. L., Guell A.E., Villagra S.M. 2001. Resistivity sounding method applied to saline horizons' determination in Colonia Loveras-San Juan Province-Argentina, Brazilian Journal of Geophysics, Vol.19 (3).

Jarvis K. D. and Knight R. J. 2002. Aquifer heterogeneity from SH-wave seismic impedance inversion, Geophysics, Vol. 67, No. 5, 1548-1557.

Kafri U. and Goldman M. (2005). The use of the time domain electromagnetic method to delineate saline groundwater in granular and carbonate aquifers and to evaluate their porosity, Journal of Applied Geophysics, 57, 167-178.

Kuras O., Meldrum P.I., Oglivey R.D., Gisbert J., Joretto S., and Sanchez Martos F. 2005. Imaging sea water intrusion in coastal aquifers with electrical resistivity tomography: initial results from the lower Andarax delta, SE Spain, Proceedings, $11^{\text {th }}$ Annual MeetingEAGENear-Surface Geophysics Conference, Palermo, Sicily, Italy.

Nielsen L., Jorgensen N, O., and Gelting P. 2007. Mapping of the freshwater lens in a coastal aquifer on the Keta Barrier (Ghana) by transient electromagnetic soundings, Journal of Applied Geophysivs, Vol. 62, 1-15.

Nguyen F., Kemna A., Antonsson P., Engesgaard P., Kuras O., Ogilvy R., Meldrum Gisbert J., Jorreto S., Pulido-Bosh A. 2009. Characterization of sea water intrusion using 2D electrical imaging, Near Surface Geophysics, Special issue on Hydrogeophyics - Methods and Processes, Vol. 7, No.5-6, 377-390.

Paritsis S.N. 2005. Simulation of seawater intrusion into the Tymbaki aquifer, South Central Crete, Greece. Report within MEDIS, Study implemented on behalf of the Department of Management of Water Resources of the Region of Crete. Heraklion, Crete, Greece.

Zhang J. and Morgan F.D. 1997. Joint seismic and electrical tomography, Ann. Symp. Environ. Geophys. Soc. (SAGEEP), Exp. Abst., 391- 395. 